\title{
INTEGRAÇÃO NACIONAL E FRAGMENTAÇÃO REGIONAL: O SENTIDO TERRITORIAL DA BR- 153 NO CENTRO-NORTE BRASILEIRO
}

\author{
TADEU Alencar ARrais ${ }^{1}$ \\ DENIS CASTILHO ${ }^{2}$ \\ Universidade Federal de Goiás \\ ONOFRE PEREIRA AURÉlio NeTO3 \\ Faculdade Alfredo Nasser
}

Resumo: A construção da Rodovia Federal BR-153, além de cumprir importante papel no processo de urbanização do território goiano-tocantinense, atendeu a uma demanda de integração do mercado nacional. Dentre as principais transformações proporcionadas por essa rede destacam-se o aumento populacional, o crescimento significativo da produção agropastoril, a dinamização do mercado urbano e as mudanças na estrutura fundiária. Analisar os impactos territoriais dessa rodovia no centro-norte brasileiro é o objetivo central deste trabalho. Para tanto, realizamos levantamento bibliográfico, ampla pesquisa documental e trabalho de campo, bem como mapeamento da rodovia, no sentido de ilustrar a sua evolução, a morfologia urbana de núcleos que a margeiam, os postos de combustíveis e as praças de pedágio planejadas para o trecho entre Anápolis e Aliança do Tocantins. Diante da importância logística da BR-153, reforçada pelo aumento das trocas regionais, a concessão à iniciativa privada representa mais que uma maneira de assegurar o seu funcionamento. $\mathrm{O}$ regime de concessão tem um sentido comercial pela garantia de lucratividade, mas também guarda um valor estratégico por envolver o controle do fluxo e, portanto, do funcionamento do território.

Palavras-chave: Rodovia Federal BR-153; Integração Nacional; Fragmentação Regional.

\footnotetext{
${ }^{1}$ Professor Associado do Instituto de Estudos Socioambientais da Universidade Federal de Goiás. Mestre em Geografia pela UFG e doutor em Geografia pela Universidade Federal Fluminense.

${ }^{2}$ Professor Adjunto do Instituto de Estudos Socioambientais da Universidade Federal de Goiás. Mestre e doutor em Geografia pela Universidade Federal de Goiás.

3 Professor da Faculdade Alfredo Nasser - UNIFAN. Mestre e dutorando em Geografia pela Universidade Federal de Goiás.
} 
NATIONAL INTEGRATION AND REGIONAL FRAGMENTATION: THE TERRITORIAL MEANING OF BR -153 IN NORTH-CENTRAL BRAZIL

Abstract:The construction of Brazilian federal highway BR-153 has played a major role in the urbanization process of the territory spanning Goiás and Tocantins states, as well as sought to integrate the national market. Among the main changes brought about by this network are population growth, significant increment of agricultural and livestock production, urban market dynamization and modifications to land ownership patterns. The main goal of this paper is to examine the territorial impacts of BR-153 on the central-north region of Brazil. To achieve this, we have carried out bibliographical, documentary, and field research, as well as mapped the highway to show its evolution, the urban morphology of settlements growing along it, petrol stations, and tollbooths to be installed between Anápolis and Aliança do Tocantins. In view of BR-153's logistical importance, boosted by an increase in regional exchanges, private sector concessions represent more than a means to ensure the highway's functionality. Its 'privatization' has a commercial purpose by guaranteeing profits, but it also reveals a strategic purpose through controlove the flow and, hence, over the functionality of the territory.

Keywords: Federal Highway BR-153; National Integration; Regional Fragmentation.

\section{Introdução}

A rodovia federal longitudinal BR-153, com seus 4.355 quilômetros de extensão, interliga o Brasil de norte a sul. O trecho goiano-tocantinense tem 1.466 quilômetros e estende-se entre os municípios de Itumbiara (GO) e Xambioá (TO). No trecho entre Anápolis (GO) e o entroncamento com a BR-226, em Wanderlândia (TO), a rodovia também é conhecida pelo nome de "Belém-Brasília", designação popular desde o período da construção da capital federal. A evolução dessa rodovia, além de influenciar o processo de urbanização do território goiano-tocantinense e, por conseguinte, a diversificação da divisão territorial do trabalho, atendeu também à demanda de integração do mercado nacional, o que ocasionou a fragmentação regional - motivo pelo qual sua construção guarda forte relação com a política territorial. Com base em revisão bibliográfica, pesquisa documental e levantamento de dados secundários, analisamos as transformações espaciais provenientes da construção da rodovia no território goiano-tocantinense. Outra etapa da pesquisa refere-se ao trabalho de campo realizado com o propósito de identificar a dinâmica dos serviços, o que resultou em mapeamento e tipologia de todos os postos de combustíveis ao longo do trecho goiano-tocantinense. Essa opção metodológica foi necessária, especialmente, porque subsidiou a análise do processo de concessão da rodovia para a inciativa privada, com cobrança de pedágio em nove praças prevista para o segundo semestre de 2015. 


\section{A rodovia e a urbanização do norte goiano}

A história da BR-153 confunde-se com a história da rodovia Belém-Brasília e, portanto, com o processo de ocupação do norte goiano-tocantinense, do sudoeste do Maranhão e da faixa leste do Pará. Ao longo do trecho que recobre os atuais estados de Goiás e Tocantins, o trajeto da BR-153 sobrepõe parte da Belém-Brasília. As diferentes denominações, no entanto, não mudam o fato de que essa rodovia, como observa Teixeira Neto (2008), tenha constituído um dos principais fatores de urbanização do território goiano-tocantinense, área que compreende os vales dos rios Araguaia e Tocantins. Estes se encontram em uma região conhecida como Bico do Papagaio, fronteira entre os estados do Tocantins, Pará e Maranhão.

A rede urbana que se construiu nesse extenso território pode ser assim resumida. No período colonial, em função da atividade aurífera e das comunicações fluviais, esteve concentrada às margens do rio Tocantins, com destaque para as cidades de Porto Nacional, Pedro Afonso, Peixe e Tocantínea. Aqui se formou o primeiro eixo de povoamento e comunicação dessa região com o norte do país e o centro do território goiano-tocantinense. A partir do segundo quartel do século XX, com a ampliação das trocas regionais e, principalmente, com o progresso das redes de circulação terrestre que partiam da área central do território goiano-tocantinense, a urbanização começou a se descolar para o centro do Tocantins, em linha que corresponde aos divisores das bacias hidrográficas dos rios Araguaia e Tocantins. Às margens da rodovia Belém-Brasília, como mostra a Figura 1, formou-se o segundo eixo de povoamento e comunicação, o que determinou a morfologia urbana linear de inúmeros povoados e cidades. 
EVOLUÇÃO DO TRAÇADO E POVOAMENTO NO TRECHO GOIANO-TOCANTINENSE DA BELÉM-BRASÍLIA

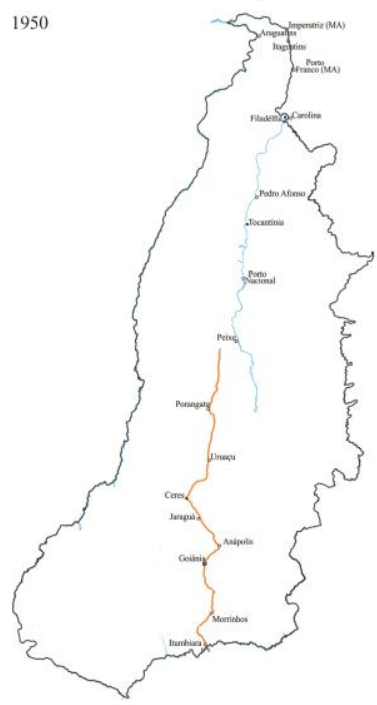

1960

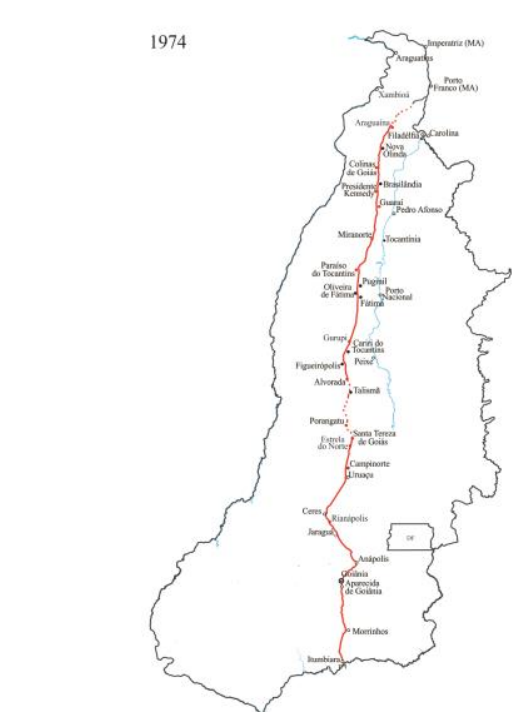

1980
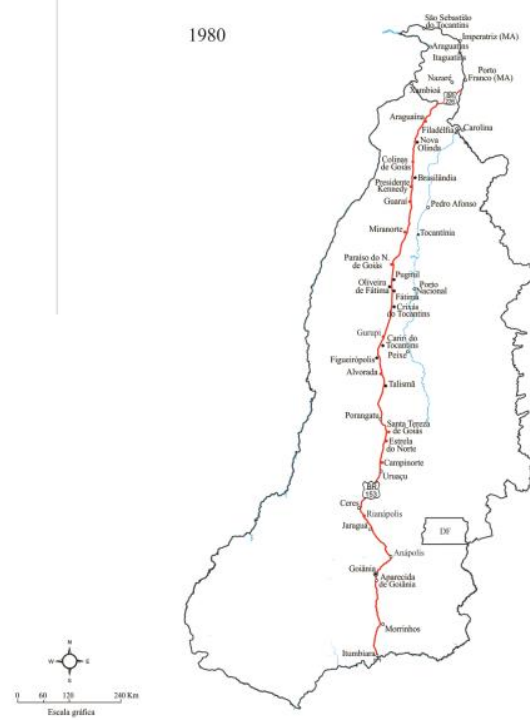

LEGENDA

Fatores de Povoamento

- Rodovia em leito natural

- Rodovia com revestimento

- Cidades que surgiram com a BR-15j

- Povoados e vilas que surgiram com a BR-153

- Cidades que surgiram por outros fatores de povoamento

- Rodovia pavimentada

- Capital do estado

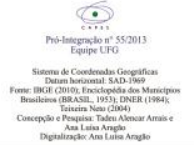

Figura 1: Evolução do traçado e do povoamento no trecho goiano-tocantinense da rodovia BR-153. 
O contexto de construção da rodovia Belém-Brasília, dando continuidade ao processo de modernização territorial em Goiás (CASTILHO, 2014), atendeu a uma demanda de integração do mercado nacional, motivo de sua relação umbilical com a edificação de Brasília durante o governo de Juscelino Kubitschek de Oliveira (19561961). O simbolismo dessa rodovia foi assim descrito nas memórias do referido presidente:

Lançadas as bases de Brasília, era tempo de estender o olhar pelo mapa e visualizar, mais uma vez, a presença do grande cruzeiro de estradas, que faria a integração nacional. Era a velha obsessão que me perseguia. A ligação do Brasil por dentro! Quando sobrevoava a Amazônia, figurava na mente a linha reta que vincularia Brasília a Belém (OLIVEIRA, 1975, p. 85).

Para o propósito da integração nacional, especialmente a partir do modal rodoviário, tornou-se imprescindível a construção de uma rodovia longitudinal que cortasse extensas áreas de florestas na Amazônia e no Cerrado. Os Decretos $\mathrm{n}^{\circ}$ 43.730, de 15 de maio de 1958 (BRASIL, 1958a), e $n^{\circ} 43.909$, de 16 de junho de 1958 (BRASIL, 1958b), respectivamente, criaram a Comissão Executiva da Rodovia Belém-Brasília (Rodobrás) e estabeleceram normas especiais para a construção da rodovia. Dentre as dificuldades a vencer, para além do isolamento regional que exigia esforço logístico magnífico, podemos mencionar a densa vegetação da floresta equatorial, especialmente na porção paraense; o regime pluvial; os solos que, desnudados por máquinas e pelo esforço braçal de milhares de trabalhadores, formavam verdadeiras trincheiras; a transposição de cursos d'água; além das dificuldades para nutrir as turmas nas diferentes frentes de trabalho.

As obras da rodovia, sob a responsabilidade do engenheiro Bernardo Sayão, considerado uma espécie de "bandeirante moderno", tanto integraram progressivamente o país quanto fragmentaram os espaços regionais. As duas maiores transformações no território goiano-tocantinense foram a urbanização - demonstrada pelo surgimento de inúmeros núcleos urbanos - e a ampliação das trocas regionais e nacionais, com impacto direto em uma economia de base agropecuária e pouco mercantilizada.

As mudanças demográficas destacadas nos municípios que correspondem à área de influência da BR-153 no território goiano-tocantinense ilustram a preponderante função da rodovia na urbanização. Na década de 1950, os municípios mais populosos foram aqueles inscritos nas áreas de influência do povoamento de Mato Grosso Goiano, como Ceres (29.522 habitantes) e Jaraguá (21.822 habitantes). Os demais municípios, como Tocantinópolis (20.758 habitantes), Porto Nacional (11.118 habitantes) e Filadélfia (13.256 habitantes), ainda estavam inscritos na lógica pretérita do povoamento que ocorrera às margens do rio Tocantins. De 1950 para 1960, período em que o leito natural da rodovia foi concluído, a população dos 
municípios em questão passou de 143.225 habitantes para 233.877 habitantes. Em 1970, a população saltou para 385.659 habitantes e em 1980, quando a pavimentação da rodovia foi concluída, para 478.729 habitantes. O fato a destacar é a mudança na hierarquia urbana regional, com predomínio, a partir de 1970, dos municípios do norte goiano-tocantinense, como Araguaína e Gurupi, em detrimento de Uruaçu e Porangatu.

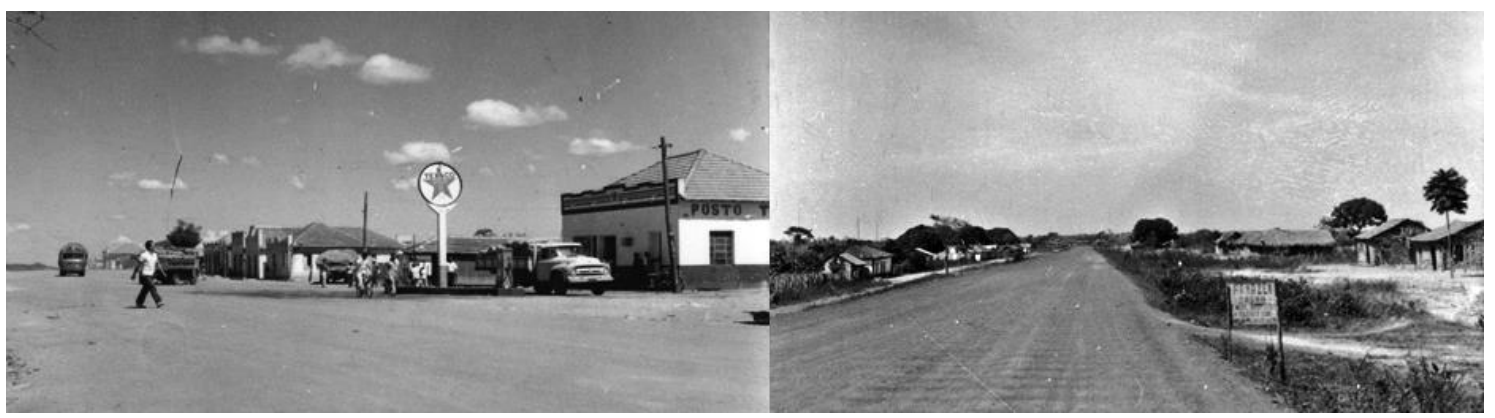

Figura 2: A foto à esquerda, de 1965, retrata aspectos da cidade de Porangatu, cujo "centro" urbano foi progressivamente deslocado para a área perpendicular à rodovia. A foto à direita, da década de 1950, mostra a cidade de Nova Olinda, cujo povoamento inicial foi marcado pelas obras da rodovia.

Fonte: Acervo Digital do IBGE (Disponível em: http://biblioteca.ibge.gov.br).

À medida que os trabalhos da rodovia avançavam para o norte, a colonização da região, motivada pela busca de trabalho, reverberava em toda a área adjacente à rodovia. O perfil da migração regional passou a ser, marcadamente, nordestino. Registros do censo demográfico de 1970 (IBGE, 1970) informam que os estados do Maranhão, Piauí e Ceará tiveram a maior participação de migrantes nos municípios atravessados pela rodovia. Em Araguaína, em 1970, 55\% dos residentes eram oriundos de outros estados. Esse percentual chegou a $40 \%$ em Guaraí e a 38\% em Paraíso. Considerando-se a população, em 1970, de municípios como Araguaína, Guaraí, Gurupi, Paraíso e Porangatu, o Maranhão contribuiu com 18.033 migrantes, o Piauí, com 7.011 migrantes, e o Ceará, com 3.437 migrantes.

A relação da região com os três estados justifica-se pela proximidade, uma vez que faz fronteira com o Maranhão e tem acesso, por ligações de estradas de rodagem, com o Piauí e o Ceará. Ela estabeleceu-se, também, pelas dificuldades encontradas nas zonas do semiárido nordestino, o que implicou intenso movimento migratório. Esse processo foi motivado pelo trabalho em, pelo menos, três segmentos, os quais eram plenamente articulados. O primeiro, como bem anotou Machado (1979), para força de trabalho em função da abertura de fazendas, derrubada de matas e formação de pastos em região típica de fronteira. $\mathrm{O}$ segundo respondeu pelos trabalhos ligados às empresas contratadas para os serviços de construção da rodovia (abertura do leito principal, aterros, terraplanagem etc.). E o 
terceiro para atividades de suporte, a exemplo do comércio (pequenas vendas, hospedarias, restaurantes, bares etc.) e dos serviços (borracharias, postos de abastecimento etc.) que surgiam em vários pontos da rodovia.

Entretanto, as mudanças não atingiram apenas a urbanização com o aumento do povoamento e a emergência de uma economia das margens, cujo fito era dar suporte às obras da rodovia, bem como à circulação que começou a se intensificar a partir da década de 1970 - quando a rodovia foi pavimentada. Ao passo que as cidades testemunharam um crescimento populacional via migração motivada pela abertura do leito principal da rodovia, a produção regional também sentiu os efeitos da progressiva integração econômica. A economia, de base primária e pouco mecanizada, guarda ainda aspectos semelhantes aos registrados no início do século $\mathrm{XX}$. Os municípios do norte goiano-tocantinense, além de mais extensos, registravam a maior concentração fundiária e o predomínio da pecuária extensiva. Aurélio Neto (2014), em seu mapeamento da pecuária na década de 1940, aponta que, nas regiões do norte goiano-tocantinense, como Pedro Afonso, Porto Nacional, Natividade e São Vicente, a relação entre efetivo bovino (oferta) e população total (demanda) era inferior a 3 , o que indicava a produção extensiva. Na economia regional predominavam produtos como arroz, milho, feijão e, principalmente, gado criado na imensidão das pastagens das grandes propriedades.

\begin{tabular}{c|c|c|c|c|c}
\hline Município & Arroz casca $(\mathrm{t})$ & Feijão $(\mathrm{t})$ & Mandioca $(\mathrm{t})$ & Milho $(\mathrm{t})$ & $\begin{array}{c}\text { Bovinos } \\
\text { (cabeças) }\end{array}$ \\
\hline Anápolis & 4.561 & 1.193 & 404 & 5.538 & 39.849 \\
\hline Araguaína & 9.154 & 848 & 2.172 & 3.190 & 42.123 \\
\hline Ceres & 18.212 & 1.394 & 1.559 & 6.137 & 36.812 \\
\hline Guaraí & 2.882 & 59 & 24 & 436 & 17.141 \\
\hline Gurupi & 7.367 & 539 & 1.328 & 1.405 & 58.386 \\
\hline Jaraguá & 5.437 & 257 & 3.351 & 1.210 & 87.581 \\
\hline Paraíso & 1.957 & 114 & 0 & 484 & 2.441 \\
\hline Porangatu & 8.254 & 547 & 1.268 & 2.504 & 58.633 \\
\hline Uruaçu & 12.282 & 4.013 & 796 & 11.684 & 63.739
\end{tabular}

Tabela 1: Produção agropecuária de municípios selecionados na área de influência da BR-153 (1970).

Fonte: Instituto Brasileiro de Geografia e Estatística (1970).

O excedente produzido, segundo Valverde e Dias (1967), tinha como destino as praças do norte brasileiro, especialmente Belém, e do sul, com destaque para Anápolis, Goiânia e São Paulo. As trocas também operavam pelo modal aéreo, a exemplo do comércio de carnes, que passava por campos de pouso em Filadélfia, Babaçulândia e Miracema do Norte, segundo a Enciclopédia dos municípios brasileiros (IBGE, 1958). Como condição primordial para a integração da produção regional, a efetivação do sistema de transporte rodoviário acarretou o aumento da circulação regional e nacional de pessoas (linhas regulares de transporte), 
mercadorias (transporte de bens de consumo) e capitais (transferências de sedes de empresas de outras regiões).

A produção do excedente também foi estimulada pelas condições ecológicas, a exemplo da produção do babaçu. Essa espécie de palmeira curinga - cujas amêndoas são utilizadas para alimentação; o caule, para estacas em todo tipo de construção; as folhas, para cobertura; e a casca, para carvão - forma o aspecto mais comum, ainda hoje, na paisagem regional, especialmente na área do Bico do Papagaio. Sobre a produção do babaçu, assim a descrevem Valverde e Dias:

Toda ela se exporta beneficiada, sob a forma de óleo, em tambores, com destino a Belém, atingindo a BR-14 através de uma rodagem que acompanha o Tocantins e vai nela entroncar a 7 quilômetros ao sul do Estreito. Somente quando essa estrada se torna intransponível, por causa das chuvas, saem as mercadorias de Porto Franco (VALVERDE \& DIAS, 1967, p. 213).

Em 1970, a produção de babaçu registrada no território goiano-tocantinense foi de 3.596 toneladas. Ela estava concentrada nos municípios de Porto Nacional (1.210 toneladas), Tocantinópolis (1.089 toneladas), Itaguatins (485 toneladas), Araguatins (370 toneladas), Araguaína (370 toneladas) e Babaçulândia (200 toneladas). Outro produto encontrado na região era a madeira. Municípios como Araguaína, Gurupi, Guaraí, Porangatu e, especialmente, Paraíso do Norte registraram expressiva produção de lenha e madeira. O último, por exemplo, teve uma produção de 257 mil metros cúbicos. À retirada da madeira somava-se a presença das madeireiras, uma das principais modalidades de indústria registradas no censo industrial de 1975 (IBGE, 1979). Em Araguaína, dos 77 estabelecimentos industriais 16 eram do ramo madeireiro. Cidades como Dueré, Guaraí, Gurupi, Miracema do Norte, Paraíso do Norte e Presidente Kennedy reuniam um total de 34 madeireiras, dado este que oferece a dimensão dessa transformação e dos impactos ambientais para a flora e a fauna regionais. Todo este movimento relacionado à terra, como destacaram Hébette e Acevedo (1980) em trabalho realizado sobre a Belém-Brasília e apoiado em inquéritos in loco entre 1975 e 1976, criou um forte esquema de especulação fundiária e conflitos em torno da posse da terra. Segundo os autores, a especulação foi estimulada pela política de incentivos fiscais, conforme é reconhecido nos dias de hoje: "os Incentivos Fiscais também foram negociados. A partir de 1966, a SUDAM aprova projetos agropecuários em toda área da Belém-Brasília e no Araguaia Paraense" (HÉBETTE \& ACEVEDO, 1980, p. 214).

É difícil separar, como produto ou mesmo como consequência, na análise da influência de uma obra de tal magnitude, a formação das cidades e a dinamização do mercado urbano e das mudanças na estrutura fundiária. $O$ fato é que, na proporção em que a construção avançava, algumas cidades passaram a formar pontos de apoio para as obras e também para a circulação. Outras, além de desempenharem essa 
função, transformaram-se em centros de gestão regional. Araguaína, por exemplo, registrou em 1980 uma população de 74.887 habitantes. Naquele momento, a rede urbana tal qual conhecemos hoje - com exceção de Palmas, capital do Tocantins havia sido desenhada e a rodovia seria o elemento responsável pela conformação de uma morfologia urbana das margens e de uma economia das margens. Machado (1979), apoiada em pesquisa de campo realizada entre os trechos de Talismã e Araguaína, no Tocantins, identificou alguns fatores responsáveis pelo surgimento dos povoados, dentre os quais a abertura de fazendas e as paradas para abastecimento. Em relação ao último fator, é interessante lembrar a analogia de Aroldo de Azevedo (1970) ao se referir à rodovia Belém-Brasília:

Não temos dúvida em classificar os postos de gasolina das áreas rurais como embriões urbanos. $\mathrm{Na}$ verdade, em grande número deles encontra o viajante não apenas o combustível para o seu veículo (automóvel de passageiros, ônibus ou caminhão) e quem possa socorrê-lo em casos de emergência (mecânicos, borracheiros), mas também alimentação e até local de hospedagem. Mas réplica perfeita dos pousos de tropas do passado (AZEVEDO, 1970, p. 246).

O fato é que a década de 1970 anunciou, além da necessidade de integração do território brasileiro, a consolidação de uma rede urbana que favorecesse a articulação do Centro-Sul com o Norte do país. Estabeleceu-se, assim, a hierarquia regional, tendo como "nós" mais importantes da rede do norte goiano-tocantinense as cidades de Araguaína, Gurupi, Paraíso e Colinas, todas situadas no Tocantins.

\section{Modernização da rede de serviços na BR-153}

A seguinte passagem de Valverde e Dias revela o processo de modernização dos serviços ao longo da rodovia:

Até 1964, entretanto, o tráfego só era assegurado na BR-14 durante a estação seca. A partir do fim daquele ano, porém, a Rodobrás deliberou manter a circulação, mesmo no período chuvoso, de modo que, hoje em dia, a BR-14 é uma estrada excepcional no Brasil, no sentido de que lá os veículos encontram o mais perfeito apoio logístico, sobretudo relativamente às demais estradas de solo compactado. Nela existem postos de gasolina, oficinas mecânicas e borracheiros, de 100 em 100 quilômetros, em média; em cada um dos 4 Distritos Rodoviários da Rodobrás (cada um deles zelando por cerca de 500 quilômetros da estrada) há 4 estações de telégrafo com serviço de radiofonia; em casos de 
atolamento, que atualmente se tornam cada vez mais raros, tratores do serviço de conservação e melhoramento da BR-14 socorrem os veículos, e, na hipótese de acidentes graves, o próprio teco-teco da Superintendência tem atendido as vítimas (VALVERDE \& DIAS, 1967, p. 335-336).

A pavimentação da rodovia, condição primordial para a melhoria da fluidez, foi concluída em 1973, conforme relatam Hébette e Acevedo. A seguinte citação dos autores ilustra as mudanças provocadas ao longo da rodovia:

A rodovia Belém-Brasília e o movimento de veículos que ela proporcionou repercutiram no emprego mediante a cadeia de serviços especificamente voltados para a manutenção do material rodante. Junto aos hotéis, pensões e restaurantes onde viajantes e motoristas repousam e se restauram, estão os postos de gasolina, as oficinas mecânicas, os postos de borracheiros, de lavagem e lubrificação dos carros (HÉBETTE \& ACEVEDO, 1980, p. 235).

As redes, como assinalado por Capel (2011), configuram a geografia dos territórios e dos centros urbanos. O perfil das cidades ao longo da BR-153 está plenamente articulado com uma rede de serviços de suporte às atividades de circulação ao longo do território goiano-tocantinense. Trata-se, de fato, de uma área de intensa movimentação, pois a integração entre o Sudeste e o Norte do país tem nesse tronco longitudinal seu mais denso vetor de circulação. Além disso, deve-se assinalar o fato nada trivial de a BR-153 ligar essa região à capital do país. Relatório produzido pela Rodobrás atesta o progressivo fluxo de veículos em determinados trechos da Belém-Brasília (BRASIL, 1960). A intensidade maior localiza-se nos trechos que articulam Ceres, Uruaçu, Anápolis e Goiânia. Outro relatório, de responsabilidade da Diretoria Rodoviária Federal, aponta que o volume médio diário (VMD) em 1976 foi de 1.228 veículos entre Porangatu e Uruaçu, de 1.808 veículos entre Jaraguá e Anápolis e de 2.825, entre Goiânia e Morrinhos (GOIÁS, 1978). A partir da década de 1970, quando a pavimentação foi concluída, o fluxo de veículos de passeio e de caminhões teve um aumento significativo.

A distância média que separava as cidades foi progressivamente reduzida em função do povoamento e da fragmentação municipal. Em 2014, a maior distância entre cidades no trecho analisado da BR-153 era de 77 quilômetros, entre Porangatu (GO) e Talismã (TO). Em 1977, para se ter uma ideia, 177 quilômetros separavam as cidades de Paraíso e Gurupi. Entre elas, atualmente encontramos as cidades de Aliança do Tocantins, Crixás do Tocantins, Fátima, Oliveira de Fátima e Pugmil, além de vilas e povoados. A intensidade do fluxo de veículos guarda relação com a densificação da rede urbana e com a evolução da integração por meio da ampliação das trocas, mas também pela evolução da motorização. Não apenas a produção é drenada, como bens manufaturados são importados - reproduzindo um padrão 
desigual de trocas. Ganha relevância tanto o transporte de cargas, com a circulação de caminhões, quanto o transporte de passageiros em escala regional e nacional. Um exemplo é a presença regular de caminhões-cegonha na BR-153, fato que denota a articulação das grandes praças de montadoras e distribuidoras de veículos, como Goiânia, Anápolis e Catalão - em Goiás - e cidades de Minas Gerais e São Paulo, com o Norte do país. No que tange à motorização, é possível supor que os melhoramentos mecânicos de veículos de passeio e carga reduziram o consumo de combustível, o que resultou em uma dinâmica de especialização e concentração dos serviços em determinados "nós" ao longo da rodovia. Um aspecto que comprova essa hipótese é a redução das borracharias ao longo da BR-153, especialmente na área norte que corresponde ao estado do Tocantins.

A rodovia determinou a morfologia dos sítios urbanos, provocando a fragmentação e o surgimento de centralidades intraurbanas nas áreas que a margeiam, como mostra a Figura 3. Desde núcleos urbanos menos densos, como Campinorte (GO), Talismã (TO), Aliança (TO) e Brasilândia (TO), até os centros que estão no topo da hierarquia urbana regional, como Araguaína (TO), Gurupi (TO) e Porangatu (GO), identificamos níveis de centralidade e presença de serviços que não atendem apenas às demandas municipais. As pesquisas da Região de Influência das Cidades (Regic), realizadas em 1993 e 2007, já demonstravam a importância de Araguaína e Gurupi que, mesmo após a consolidação de Palmas (TO), continuam a exercer importante influência no fluxo de mercadorias e serviços regionais (IBGE, 1993 e 2007).

O caso de Araguaína é exemplar. Ao longo de aproximadamente dez quilômetros da rodovia duplicada que secciona o espaço urbano entre leste e oeste, encontramos concessionárias (Volvo, Toyota, Fiat e Chevrolet) que atendem a demanda regional, com representações e vendas para a região do Bico do Papagaio, bem como serviços diretamente estimulados pela presença da rodovia (mecânicas, autopeças, retíficas, estabelecimentos que vendem molas e lubrificantes, postos de combustíveis etc.). Esse desenho repete-se, em menor intensidade, nas cidades de Uruaçu (GO), Porangatu (GO), Gurupi (TO), Guaraí (TO) e Paraíso (TO). No caso de centros urbanos menos populosos, a extensão da rodovia atinge em média um quilômetro no espaço urbano, com residências e serviços distribuídos ao longo das margens. É comum que a rodovia seja um divisor dos sítios urbanos a leste e a oeste, influenciando diretamente a morfologia urbana e o valor do solo, dado que a localização tornou-se uma positividade. É difícil imaginar o funcionamento dos serviços nesses municípios dinâmicos sem considerar a fluidez da rodovia. Mas a centralidade, especialmente dos serviços, além de atender a rodovia, também atendeu ao estímulo das atividades agropecuárias. A partir de Anápolis, passando por Porangatu, Gurupi e Araguaína, a rodovia abrange área em pleno processo de modernização agropecuária, com destaque para a produção de grãos. 


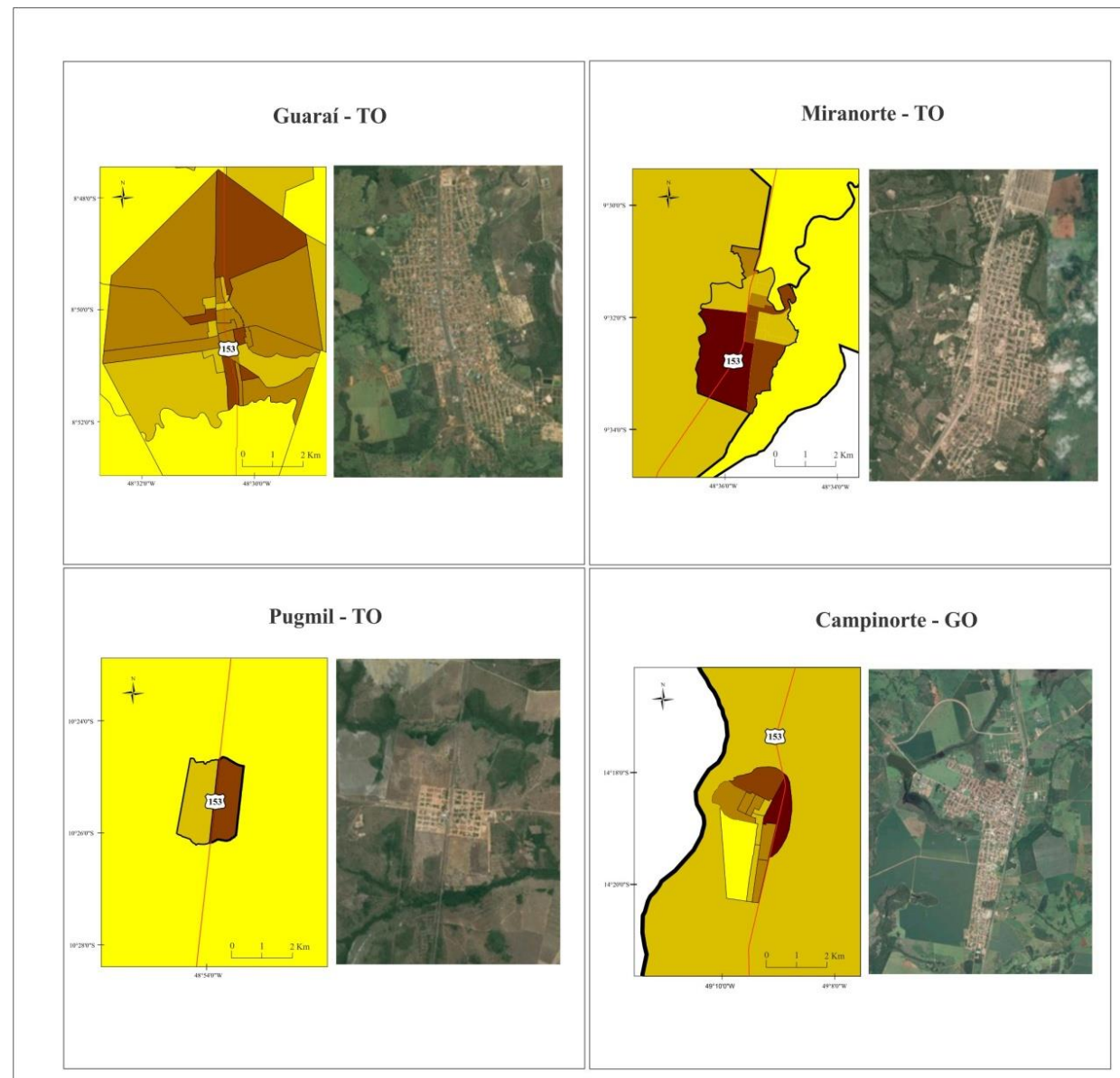

População residente, por setor censitário (2010)

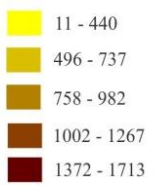

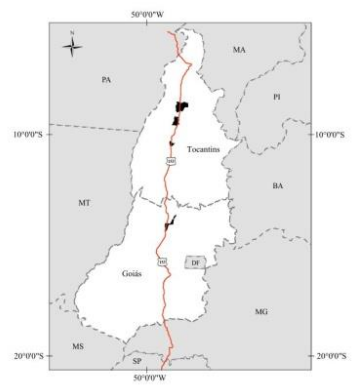

Sistema de Coordenadas Geográfica - Datum: SIRGAS 2000

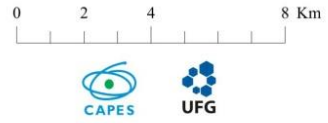

Pró-Integração-CAPES. Edital n. ${ }^{\circ}$ 55/2013

Fonte:

GOOGLE - Digital Globe Map, 2015

IBGE - Populacão residente por setor censitário, 2010

IBGE - Shapefile das Rodovias Federais

IBGE - Shapefile dos Municipios Brasileiros

IBGE - Shapefile dos Estados Brasileiros

Elaboração: ARRAIS, T. A; AURÉLIO NETO, O; CASTILHO, D.

Figura 3: Morfologia dos sítios urbanos ao longo da BR-153. 
A dinâmica econômica motivada pela rodovia também se traduz, de modo específico, na oferta de emprego formal. A análise da composição do emprego formal ao longo da BR-153 comprova tal fato. Mas nem todos os municípios são atingidos da mesma forma. Nos principais municípios da rede (Uruaçu, Porangatu, Gurupi, Paraíso e Araguaína), o comércio e os serviços ofereceram, em 2013, mais de $51 \%$ do total de empregos formais no âmbito municipal. Esse perfil não aparece nos municípios de menor peso demográfico, como Talismã (TO) ou mesmo Presidente Kennedy (TO), cujo perfil da administração pública é predominante na geração de emprego formal. Observadas as ocupações com maiores estoques de emprego, também confirmamos a influência da rodovia. Nos municípios mais populosos, como Araguaína (TO), Gurupi (TO) e Porangatu (GO), a ocupação "vendedor de comércio varejista" aparece em primeiro lugar no estoque de emprego formal. Um dado indicativo, além do varejo, refere-se à ocupação denominada "motorista de caminhão" (rotas regionais e internacionais). Esta ocupação aparece em terceiro lugar no estoque de empregos em Uruaçu (GO) e em quinto lugar em Porangatu (GO), Paraíso (TO), Gurupi (TO) e Araguaína (TO), o que indica, claramente, a força da localização e o destaque do setor de transporte na região. Mas nada traduz tão fortemente a influência da rodovia como a análise do perfil do emprego formal no município de Fortaleza do Tabocão (TO), onde os frentistas aparecem em primeiro lugar no estoque de emprego. Nesse município, mais que em qualquer outro, o posto de combustível, pelos serviços que oferece, transformou-se em uma centralidade. Mazuras (2013, p.138) ressalta que "o Auto Posto e Churrascaria Tabocão, fundado em 1987, chega a reunir 2,5 mil visitantes nos dias de pico". Esse número, mesmo considerando o ano de 2014, é superior à população total do município, de 2.542 habitantes (BRASIL, 2014).

Uma pesquisa de campo realizada ao longo do trecho goiano-tocantinense da BR153, em setembro de 2014, objetivou verificar a dinâmica dos serviços relacionados diretamente à rodovia. Entre Anápolis (GO) e Xambioá (TO), identificamos 119 postos de combustíveis, dos quais 80 eram localizados em áreas urbanas e 39, em áreas rurais. Do total dos ativos, 32 são da BR-Petrobrás, 17 da Ipiranga, 10 da Shell, cinco da Rede Carreteiro, quatro da ALE e um da Rede Tabocão. Bandeiras locais e postos sem definição de rede somaram 26. A escolha dos locais de instalação dos postos justifica-se pelo fato de se constituírem como elementos fixos da paisagem, os quais se configuram como "nós" ou pontos de serviços fundamentais da rede rodoviária. Os postos, conforme revela a Figura 4, foram classificados a partir da oferta de serviços. O objetivo foi identificar os estabelecimentos com a maior oferta dos serviços mais significativos para a logística regional e nacional, seja para o suporte mecânico (autoelétrica, autopeças, mecânica etc.), seja para o suporte aos caminhoneiros e/ou motoristas (estacionamento para caminhões, hotéis, churrascaria etc.). 


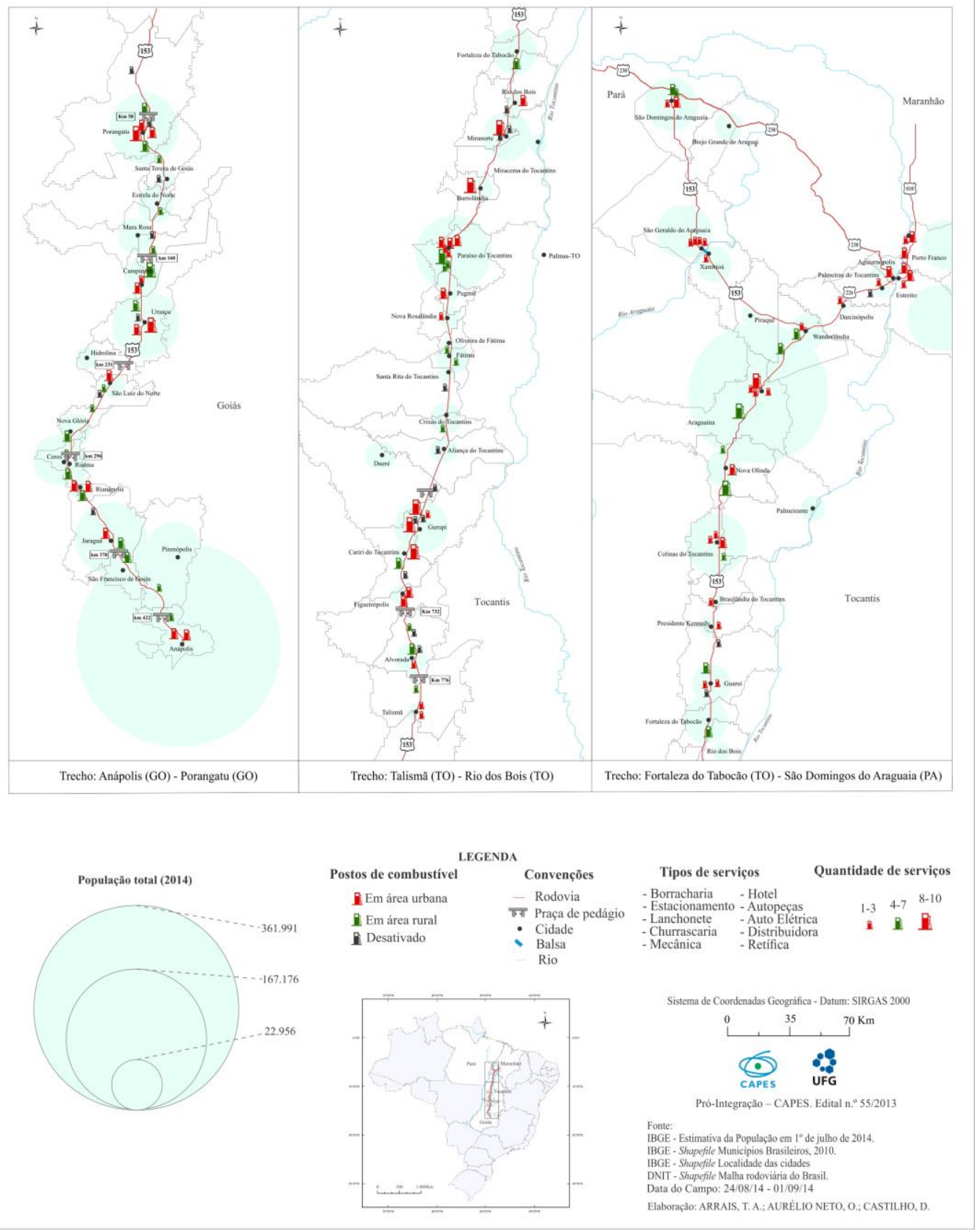

Figura 4: Distribuição dos postos de combustíveis e praças de pedágio no trecho Anápolis (GO)São Domingos do Araguaia (PA) da rodovia BR-153. 
A Figura 4 divide a área de pesquisa na rodovia (correspondente a 1.679,2 quilômetros, entre Anápolis-GO e o entroncamento da BR-153 com a BR-230, em São Domingos do Araguaia-PA) em três trechos. O primeiro, entre Anápolis e Porangatu, possui maior densidade demográfica e fluxo de veículos. Nesse trecho, de 439,8 quilômetros, identificamos a presença de 35 postos de combustíveis, sendo 18 rurais e 12 urbanos. Também registramos as menores distâncias entre os postos, o que se explica pela presença de inúmeras cidades, vilas e povoados. A maior distância entre um posto e outro foi de 35,3 quilômetros, verificada entre um estabelecimento localizado em área rural do município de Porangatu (GO) e outro localizado na área urbana do município de Talismã (TO). A maior parte dos postos apresenta infraestrutura básica, com estacionamento, churrascaria, borracharia, mecânica e autoelétrica.

O segundo trecho abrange 426,1 quilômetros da rodovia, entre os municípios de Talismã (TO) e Fortaleza do Tabocão (TO). Este é caracterizado pela polarização das cidades de Gurupi e Paraíso do Tocantins, a área com maior concentração de postos e oferta de comércio e serviços relacionados à logística. Ressalta-se que, nesse trecho, há 11 postos fechados, localizados, em sua maioria, no perímetro rural. A maior distância entre os postos foi de 41,8 quilômetros, registrada entre Paraíso do Tocantins (TO) e Barrolândia (TO).

O terceiro trecho compreende 813,3 quilômetros, entre Fortaleza do Tabocão (TO) e São Domingos do Araguaia (PA). Há 31 postos de combustíveis, sendo oito localizados em áreas rurais e 21 em áreas urbanas, além de dois fechados. $\mathrm{O}$ destaque, sem dúvida, é para o trecho entre Nova Olinda e Araguaína, que reúne os postos com melhor infraestrutura e capilaridade na rede, a exemplo do Posto Marajó (Figura 5), o qual possui ampla área para estacionamento, serviços especializados para frotas e um shopping com lojas, lanchonetes e restaurantes. Os postos constituem importantes centralidades ao longo da rodovia, tanto para viajantes como para residentes dos municípios próximos. Ressalta-se, também, o estoque de combustível ao longo da rodovia, especialmente em postos como o Tabocão e o Marajó. O primeiro possui uma tancagem de 525 mil litros de combustível e o segundo, de 375 mil litros. Desses, o destaque vai para o óleo diesel, que representa $74 \%$ no Tabocão e $84 \%$ no Marajó. Isso mostra que o fluxo demanda um significativo estoque de óleo diesel, especialmente em rodovias interestaduais como a BR-153. A tancagem de postos localizados em regiões centrais de cidades como Palmas e Anápolis, por exemplo, é bastante inferior. No posto Central da capital tocantinense, a tancagem é de 90 mil litros, dos quais 33\% são de óleo diesel. No posto São Francisco, localizado na área central de Anápolis (bairro Jundiaí), a tancagem também é de 90 mil litros, dos quais apenas 16\% são de óleo diesel. 


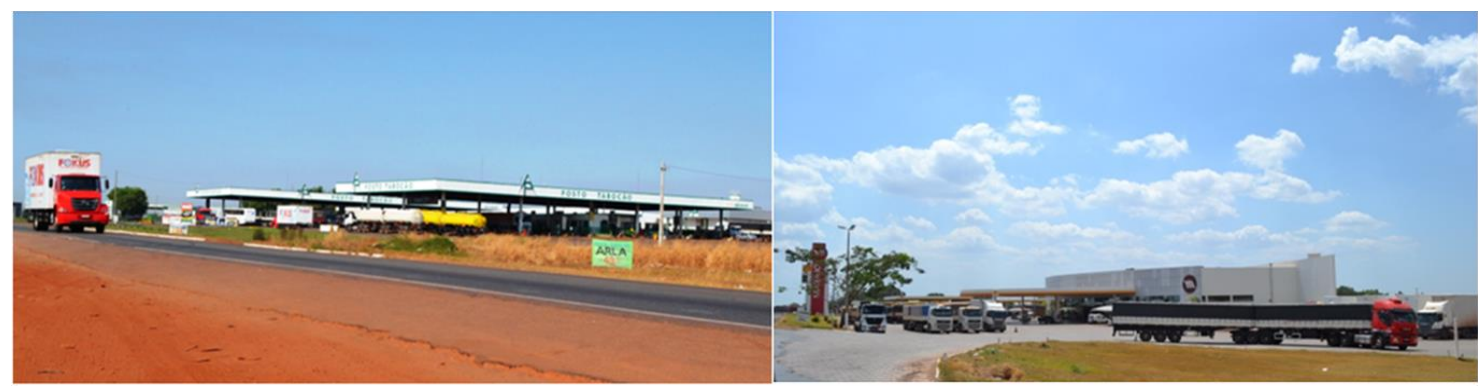

Figura 5: Auto Posto Tabocão no município de Fortaleza do Tabocão (TO), e Posto Marajó, no município de Nova Olinda (TO).

Fonte: Fotografias dos autores (2014).

Ainda no que se refere ao terceiro trecho, na altura de Wanderlândia (TO) a BR153 bifurca-se com destino a Xambioá (TO), cuja passagem para São Geraldo do Araguaia (PA) ocorre por meio de balsa. O fluxo de veículos nessa parte do trecho em nada se compara ao do trecho longitudinal da rodovia denominado BelémBrasília, cujo fluxo principal segue em direção à cidade de Estreito (MA) pela BR226 e BR-010. No subtrecho Wanderlândia-Xambioá, registramos a maior distância entre postos de combustíveis, a saber, 84 quilômetros. $\mathrm{O}$ fato é que a fluidez ao longo da BR-153, tanto no trecho goiano como no tocantinense, ilustra as trocas regionais. Se, por um lado, a rodovia promove uma integração em escala nacional, por outro, contribui com a fragmentação de espaços urbanos e regionais, o que pode ser traduzido, por exemplo, pelo surgimento de núcleos urbanos, a criação de municípios e a ampliação da divisão territorial do trabalho. Diante de um território cada vez mais diversificado, a fluidez ganha ainda mais importância e o seu controle passa a representar participação no controle do próprio território. A concessão da BR-153 à iniciativa privada é um caso ilustrativo de todo esse processo.

\section{A concessão e o controle da fluidez}

Em 23 de maio de 2014, como amplamente divulgado pela imprensa brasileira, a Galvão Engenharia S.A. venceu o leilão de concessão para exploração e implementação de pedágio no trecho de 624,8 quilômetros da rodovia BR-153, no entroncamento da rodovia BR-060 - em Anápolis - com a rodovia estadual TO-070, em Aliança do Tocantins. Também disputavam a concessão a Triunfo Participações e Investimentos, que ofereceu tarifa de $\mathrm{R} \$ 9,128$ por 100 quilômetros, e o Consórcio Norte-Sul, formado pela EcoRodovias, Queiroz Galvão e Coimex, que ofereceu tarifa de $\mathrm{R} \$ 7,238$ por 100 quilômetros. O resultado da concessão foi homologado 
pela Resolução $\mathrm{n}^{\circ} 4.353$, de 25 de junho de $2014,{ }^{4}$ e o contrato foi assinado em 12 de setembro do mesmo ano com a Agência Nacional de Transportes Terrestres (ANTT). A concessão, cujo prazo é de 30 anos, envolve serviços de duplicação, manutenção, conservação, operação, implantação de melhorias e ampliação de capacidade da rodovia. $\mathrm{O}$ trecho abrange os seguintes municípios goianos: Anápolis, São Francisco de Goiás, Pirenópolis, Jaraguá, Rialma, Ceres, Nova Glória, Hidrolina, São Luiz do Norte, Uruaçu, Campinorte, Estrela do Norte, Mara Rosa, Santa Tereza de Goiás e Porangatu. No estado tocantinense, os municípios abrangidos pelo trecho concedido são: Talismã, Cariri do Tocantins, Alvorada, Santa Rita do Tocantins, Figueirópolis, Gurupi, Dueré e Aliança do Tocantins.

De acordo com o contrato, o trecho terá nove praças de pedágio e as tarifas poderão ser cobradas somente após a conclusão de $10 \%$ das obras de duplicação, o que equivale a 60 quilômetros - considerando a extensão do trecho a ser duplicado. Essa exigência consta no Programa de Exploração de Rodovias (PER) do Edital de Concessão $n^{\circ} 1 / 2014$ (BRASIL, 2014). O restante deverá ser completamente duplicado nos cinco primeiros anos da concessão. Atualmente, dos 624,8 quilômetros de extensão, 598,3 são de pista simples e o restante, 26,5 quilômetros, são de pista dupla com canteiro central. Além desses, também há 9,2 quilômetros de vias marginas, dos quais 2,8 não estão pavimentados.

De acordo com o PER, a duplicação será realizada por subtrechos e deve ser concluída em 48 meses após a data de expedição da licença de instalação (BRASIL, 2014). No primeiro e segundo anos deverão ser duplicados 95,8 e 143,6 quilômetros de extensão, respectivamente. Outros 203,4 quilômetros serão duplicados no terceiro ano e 155,6 quilômetros no quarto. O contrato, nesse sentido, exige o total de 598,3 quilômetros de trecho duplicado. Além dos trabalhos de recuperação, duplicação e manutenção, também estão previstas a construção de vias marginais, a conservação das vias e a oferta de serviços operacionais, tais como ouvidoria, atendimento préhospitalar, socorro mecânico, combate a incêndios etc. Após a duplicação de cada subtrecho, o PER exige da concessionária o prazo de 12 meses para a implementação de vias marginais referentes ao subtrecho. Segundo estimativas do governo, serão investidos 4,3 bilhões de reais durante as três décadas da concessão.

Se, por um lado, há o investimento realizado pela concessionária, por outro, há um preço a ser pago pelo usuário. De acordo com o contrato, "a concessão é remunerada mediante cobrança de Tarifa de Pedágio" (BRASIL, 2014, p. 9). No caso da concessionária Galvão BR-153, o valor inicial da tarifa será de R $\$ 0,04979$ (quatro mil novecentos e setenta e nove centésimos de milésimo de real), que equivale a $\mathrm{R} \$ 4,979$ por 100 quilômetros. O contrato ressalta que a cobrança terá início somente após

4 Disponível em: <http://www.jusbrasil.com.br/diarios/72475223/dou-secao-1-02-07-2014-pg-189>. Acessado em: 17 jan. 2015. 
a conclusão dos Trabalhos Iniciais no Sistema Rodoviário, a implantação de $10 \%$ (dez por cento) da extensão total das obras de duplicação previstas no PER, a implantação de praça de pedágio (...), bem como da entrega do programa de redução de acidentes e do cadastro do passivo ambiental. (...). Somente serão consideradas implantadas as pistas duplas e, portanto, como atendidas as metas de duplicação indicadas no PER e neste Contrato, quando concluídas as obras de duplicação e as respectivas melhorias, quando essas pistas e melhorias forem abertas ao tráfego (BRASIL, 2014, p. 34).

Considerando-se a aplicação da tarifa somada ao fluxo da rodovia, especialmente nos trechos escolhidos para implantação das praças de pedágio, não é difícil imaginar o porquê da taxa de lucratividade da empresa estar assegurada em poucos anos. Além dos multiplicadores tarifários de acordo com a categoria de veículo, há que se levar em conta o fluxo. Mesmo no último ano, em que houve a contagem volumétrica por VMD no trecho goiano-tocantinense da BR-153, nota-se a expressividade dos números. O VMD registrado em 2001, por exemplo, foi de 5.876 veículos no posto de contagem Floresta, próximo a Jaraguá (GO), e de 3.310 veículos no posto de contagem de Gurupi (TO) (DNIT, 2001).

Estudos de tráfego de novas concessões rodoviárias federais, correspondentes ao trecho goiano-tocantinense da BR-1535, registram projeções de fluxo para todas as praças de pedágio até o término da concessão. A projeção de tráfego na praça planejada próxima a Jaraguá (GO) é de 11.314 veículos/dia em 2015 e 12.143 veículos/dia em 2020. No caso da praça planejada próxima à cidade de Gurupi (TO), a projeção é de 7.078 veículos/dia em 2015 e de 8.213 veículos/dia em 2020. Essa projeção considera o VMD de todas as categorias de veículos. Também prevê a concorrência com a Ferrovia Norte-Sul, uma vez que significativa parcela de grãos e combustíveis, além de outros produtos, será transportada por ela. Levando-se em conta apenas a categoria de caminhões (com cinco, seis, sete e nove eixos), a projeção do VMD para 2015 nas praças próximas a Jaraguá e Gurupi é de 1.904 e 865 caminhões, respectivamente. Considerando-se o fluxo total de veículos em todas as nove praças do trecho concedido, a projeção prevê 90.602 veículos passando diariamente pelos pedágios em 2015 e 101.486 veículos em 2020.

Além da expressividade dos números de fluxo, é importante ressaltar que os nove locais escolhidos para implantação das praças obedecem a uma estratégia que assegura o tráfego pelos postos tarifários e, por conseguinte, o controle do fluxo

5 Os estudos são divulgados pela ANTT no seguinte endereço eletrônico: <http://3etapaconcessoes.antt.gov.br/index.php/content/view/2696/Lote_3.html>. Acessado em: 02 mar. 2015. 
rodoviário. A praça de pedágio do quilômetro 370, por exemplo, planejada entre o entroncamento com a BR-070 e com a GO-080, abarcará o fluxo de veículos entre a porção norte da BR-153 - também de municípios como Goianésia - e a Região Metropolitana de Goiânia. Mas, caso o fluxo siga em direção a Brasília, passará por outra praça de pedágio planejada para o quilômetro 422, próxima a Anápolis. Considerando-se todo o trecho concedido à empresa Galvão, aquele que corta a porção central de Goiás é o que mais possui alternativas de caminho em direção à capital. Da Microrregião de Ceres, por exemplo, é possível utilizar as rodovias estaduais GO-154 e GO-230. No entanto, considerando-se o fluxo principal da BR153, ou seja, aquele que promove as trocas com o Norte do país, há praças de pedágio planejadas em locais muito bem posicionados para receber as tarifas. Podemos mencionar aquelas do quilômetro 296 (próximo a Ceres e Rialma), do quilômetro 231 (próximo a São Luiz do Norte) e do quilômetro 160 (entre os entroncamentos com a GO-428 e GO-239). Além do fluxo regular da BR-153, esta praça controlará as trocas entre a área que abarca municípios como Porangatu, Minaçu e Mara Rosa e a área que abrange municípios como Uruaçu, Campinorte e Niquelândia.

No caso do território tocantinense, dada a maior dependência em relação à BR153, além do fluxo que promove as trocas estaduais, significativa parcela da circulação interna do estado passa por essa rodovia. Mesmo assim, as três praças de pedágio planejadas para Tocantins estão em pontos estratégicos para o controle do fluxo, a exemplo da praça do quilômetro 776 (próximo a Alvorada) e da praça do quilômetro 732 (próximo a Figueirópolis). Ambas estão posicionadas para controlar o fluxo tanto do sentido norte-sul da rodovia como do sentido sul-norte, fluxo esse que segue por rotas alternativas em direção a Palmas.

A estratégia de localização das praças de pedágio indica um controle otimizado do fluxo, o que assegura, por consequência, maior número de usuários para cobrança de pedágio. Mas além dessa forma de assegurar a taxa de lucratividade da concessionária, o contrato garante o equilíbrio econômico-financeiro da empresa por meio, por exemplo, do reajuste do valor da tarifa de pedágio, com o apoio legal e a contribuição do Poder Estadual. Isso significa que a concessão é um grande negócio no Brasil. Considerando que o trecho a ser operado é de fundamental importância para o escoamento de grãos e combustíveis do centro-norte do país, bem como para a produção de mineradoras do norte goiano e para as trocas regionais, torna-se evidente que a concessão também possui um valor eminentemente estratégico.

O envolvimento da iniciativa privada com redes fundamentais para o funcionamento do território não é recente. Nogueira (1977) cita a existência de estradas particulares já na década de 1920 no sul de Goiás. Não podemos esquecer que há partes da rodovia BR-153 já privatizadas, a exemplo da balsa entre Xambioá (TO) e São Geraldo do Araguaia (PA). O regime atual de concessão, além disso, possui duas características fundamentais que dizem respeito a seu sentido territorial. 
Primeiro, a característica mercantil em função da garantia de lucratividade da empresa. Segundo, o sentido estratégico diante do controle do fluxo de importante rodovia brasileira. Está em jogo, por conseguinte, o controle de uma rede fundamental para o funcionamento do território nacional.

O regime de concessão de rodovias, portanto, não interfere apenas no modo como as vias serão recuperadas, ampliadas e mantidas, mas, essencialmente, no controle das trocas regionais e, por consequência, na integração nacional. Isso ajuda a compreender o porquê do interesse pela BR-153. Segundo informações disponíveis no site da empresa Galvão, o contrato de concessão com a BR-153 é o maior empreendimento de longo prazo do grupo até o momento ${ }^{6}$.

A rodovia federal BR-153 é um eixo que se torna a cada dia mais importante para a logística nacional. O processo de concessão, nesse sentido, não se dá ao acaso. Ademais, é importante lembrar que o trecho da BR-153 entre Anápolis e Itumbiara foi concedido à empresa Triunfo e que as praças de pedágio já estão em construção. Ele inclui o trecho da BR-060 entre Brasília e Goiânia, sendo o trecho entre Anápolis e a capital do estado coincidente com a rodovia BR-153. Isso significa que todo o trecho goiano dessa rodovia está "privatizado". A Ferrovia Norte-Sul, outra importante rede que possui a mesma direção da BR-153, por sua natureza, já é privada. É interessante observar que o processo de concessão de rodovias em Goiás e Tocantins, pelo menos nesta fase inicial, segue a direção sul-norte. Elas tomarão outros rumos, certamente. Mas o que chama atenção é o fato de estar em jogo não apenas a integração do território no sentido norte-sul, mas especialmente o controle da fluidez.

Dentre outros fatores, isso revela a importância logística das redes de transportes que ligam o Brasil de sul a norte e de leste a oeste, bastando lembrar o papel de radiais como a BR-060. Mas também suscita uma discussão que envolve conflitos de interesses, como salientado por Castilho (2012). Tais conflitos abrangem, além da arena macroeconômica, outras instâncias, a exemplo dos comerciantes das malhas urbanas marginais e dos trabalhadores do mercado informal dispostos pelas margens da rodovia (ver Figura 6).

${ }^{6}$ Disponível em: 〈http://www.galvao.com/quemsomos.aspx>. Acessado em: 15 jan. 2015. 


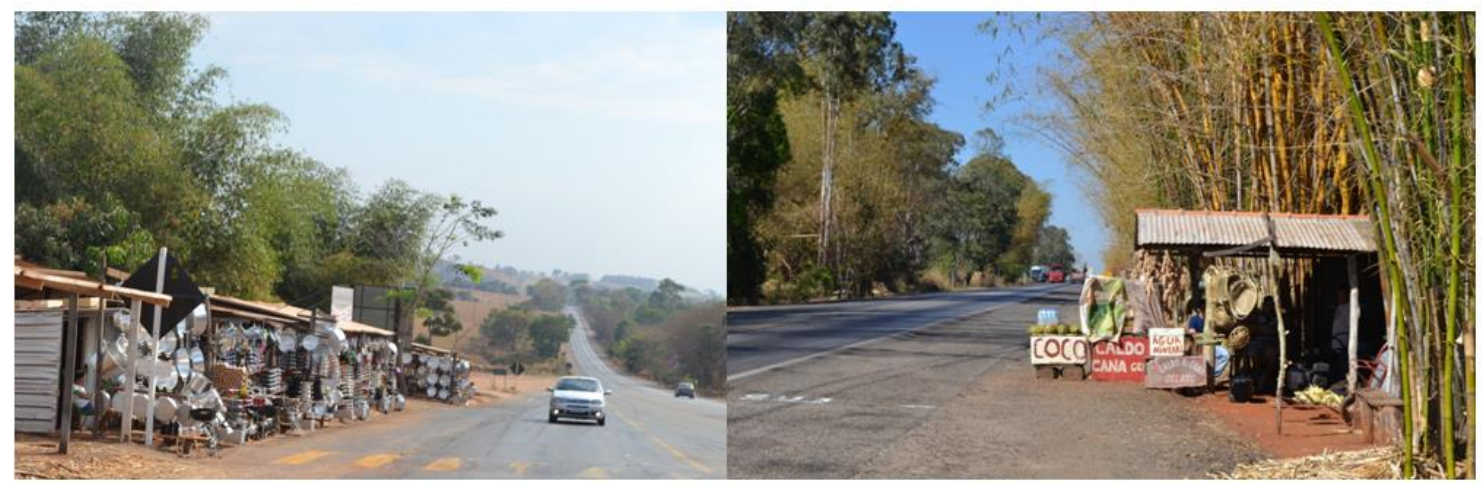

Figura 6: Mercado informal às margens da rodovia federal BR-153.

Fonte: Fotografias dos autores (2014).

Chama atenção a diversidade de produtos comercializados. São pratos regionais (chambari, galinha caipira, arroz com pequi etc.), bebidas (caldo de cana, água de coco, sucos naturais etc.), produtos artesanais, panelas, tecidos, temperos engarrafados, doces embalados, remédios caseiros, castanhas, grãos, frutas etc. Se, por um lado, algumas pessoas ocupam as margens da rodovia apenas em função do comércio, por outro, uma significativa parcela reside nelas - especialmente entre os municípios de Jaraguá e Santa Tereza de Goiás, em áreas de propriedade da União. Alguns moradores vivem nessas condições há mais de 30 anos, como é o caso de trabalhadores nas proximidades da cidade de Uruaçu.

As desapropriações estão previstas no contrato de concessão, cabendo à concessionária, "entidade delegada do Poder Concedente, promover desapropriações, servidões administrativas, propor limitações administrativas e ocupar provisoriamente bens imóveis necessários a execução e conservação de obras e serviços vinculados a Concessão" (BRASIL, 2014, p. 16). Ao término das desapropriações, o contrato exige relatório que informe a inexistência de ocupações irregulares na faixa de domínio. Ocorre que, ao mesmo tempo em que demanda o esforço da concessionária em promover a liberação de forma "amigável" perante os proprietários ou possuidores de áreas destinadas à ampliação, o contrato informa que 'a concessionária deverá arcar com todos os custos e despesas relacionados à execução do plano de desocupação'.

Não é observado no contrato qualquer incentivo ou exigência que denote, de fato, preocupação e responsabilidade com o destino dos trabalhadores e famílias que vivem há décadas nessas localidades. As desapropriações acontecerão, mas não estarão isentas de conflitos. A evolução dessa rede rodoviária, assim como as transformações promovidas por sua influência, portanto, demonstram a importância que ela representa para a integração nacional, mas também evidenciam o seu sentido 
político e o modo como importantes redes técnicas são absorvidas em benefício de determinados grupos e em detrimento de significativa parcela de outros.

\section{Considerações Finais}

A análise apresentada neste estudo expõe o importante papel da rodovia federal BR-153 em duas escalas. A primeira responde pela integração dos fluxos nacionais, especialmente mercadorias, uma vez que esta rodovia constitui eixo de integração entre o centro-norte e o sudeste do território brasileiro. A segunda escala é regional, com influência direta na rede urbana e na morfologia dos sítios urbanos que passam a depender, funcionalmente, do fluxo de cargas e pessoas. Mas a integração é acompanhada por alterações na divisão territorial do trabalho, bem como pelo controle do fluxo. $\mathrm{O}$ atual processo de concessão é uma prova disso.

Cabe ressaltar, a esta altura das discussões, que a "privatização" da BR-153 possui dois sentidos que ajudam a entender o modo como importantes redes no Brasil vêm sendo apropriadas nos últimos anos. São eles, o comercial e o estratégico. O primeiro explica-se pelo regime de concessão rodoviária no país, o qual prevê altas taxas de lucratividade às empresas. Ao Estado, em projetos dessa natureza, cabe - como assinalou Harvey (2008) - “(...) criar e preservar uma estrutura institucional apropriada a essas práticas" (2008, p. 1). O segundo justificase pelo fato de estar em jogo o controle do fluxo e, por consequência, o funcionamento do território. O que demonstra que o processo de integração nacional e de fragmentação regional guarda forte relação com os interesses de grupos empresariais e, por conseguinte, com a política territorial. É por tal motivo que as redes não podem ser compreendidas como mera "abstração", fato destacado por Santos (1997).

\section{Bibliografia}

ARRAIS, T. A. (2013) A produção do território goiano - economia, urbanização e metropolização. Goiânia: Editora da UFG. 222 p.

AURÉLIO NETO, O. P. (2014) Pecuária goiana: a tecnicização do espaço rural e a internacionalização do agronegócio da carne bovina (1920-2012). 233 f. Dissertação (Mestrado em Geografia) - IESA, Universidade Federal de Goiás. Goiânia.

AZEVEDO, A. (1970) As cidades. In: AZEVEDO, A. (org.). Brasil - a terra e o homem. Vol. 2. São Paulo: Companhia Editora Nacional. pp. 211-282.

BRASIL. (1958a) Decreto $n^{\circ} 43.710$, de 15 de Maio de 1958. Cria, na Superintendência do Plano de valorização Econômica da Amazônia, a Comissão Executiva da Rodovia Belém-Pará. Disponível em: 
<http://www2.camara.leg.br/legin/fed/decret/1950-1959/decreto-43710-15-maio1958-382550-publicacaooriginal-1-pe.html>. Acessado em: 08 set. 2014.

. (1958b) Decreto $n^{\circ} 43.909$, de 16 de Junho de 1958. Aprova as "Normas Especiais para a construção da rodovia Belém Brasília", e de regulamentação das atividades administrativas da "Rodobrás". Disponível em:

$<$ http://www2.camara.leg.br/legin/fed/decret/1950-1959/decreto-43909-16-junho1958-383078-norma-pe.html>. Acessado em: 08 set. 2014.

. (2014) Edital $n^{o} 11 / 2014$. Rodovia Federal BR-153/TO/GO: trecho de 624,8 $\mathrm{km}$ da rodovia BR-153, entre o entroncamento da BR-060 em Anápolis, no estado de Goiás, e o entroncamento com a TO-070 (Oeste) em Aliança do Tocantins, Brasília: Agência Nacional de Transportes Terrestres; Ministério dos Transportes.

(1960) Rodovia Belém-Brasília, a rodovia da unidade nacional e suas implicações de ordem técnica, econômica e política, Brasília: Presidência da República, Comissão Executiva da Rodovia Belém-Brasília.

. (1958c) Rodovia da unidade nacional. Rio de Janeiro: SPVEA.

CAPEL, H. (2011) Los ferro-carriles en la ciudad. Redes técnicas y configuración del espacio urbano. Barcelona: Fundación de los Ferrocarriles Españoles. CASTILHO, D. (2012) Estado e rede de transportes em Goiás-Brasil (18891950). Scripta Nova. Revista Electrónica de Geografía y Ciencias Sociales. Barcelona: Universidad de Barcelona, 1 de noviembre de 2012, vol. XVI, $\mathrm{n}^{\circ} 418$ (67). Disponível em: <http://www.ub.es/geocrit/sn/sn-418/sn-418-67.htm>. Acessado em: 18 jan. 2014.

. (2014) Modernização territorial e redes técnicas em Goiás. 221 f. Tese (Doutorado em Geografia) - Universidade Federal de Goiás. Goiânia-GO.

DEPARTAMENTO NACIONAL DE INFRAESTRUTURA DE TRANSPORTE (DNIT). (2001). Disponível em: <http://www1.dnit.gov.br/rodovias/contagem/index.htm>. Acessado em: 18 jan. 2014.

GOIÁS (Estado). (1978) Anuário estatístico de Goiás, vol. 1. Goiânia: Secretaria de Planejamento e Coordenação. Goiânia.

HARVEY, D. (2008) O neoliberalismo - história e implicações. São Paulo: Loyola. HÉBETTE, J; ACEVEDO, R. E. (1980) Mobilidade do trabalho e fronteira Amazônica: a Belém-Brasília. Disponível em: 〈http://www.abep.nepo.unicamp.br/docs/anais/pdf/1980/T80V01A05.pdf $>$. pp.187241.

INSTITUTO BRASILEIRO DE GEOGRAFIA E ESTATÍSTICA (IBGE). (1970) Censo agropecuário 1970 - Goiás. Rio de Janeiro: IBGE. . (1979) Censo industrial - Goiás, vol. 2, tomo 23. Rio de Janeiro: IBGE. . (1980) Censo demográfico - 1980. Rio de Janeiro: IBGE. 243 p. . (1984) Censo industrial. Dados gerais - Goiás. Rio de Janeiro: IBGE. (1958) Enciclopédia dos municípios brasileiros, vol. XXXV. Rio de Janeiro: IBGE. 
. (1993) Regiões de influência das cidades: 1993. Rio de Janeiro: IBGE.

(2007) Regiões de influência das cidades: 2007. Rio de Janeiro: IBGE. MACHADO, L. O. (1979) Urbanização e política de integração no norte de Goiás. 198 f. Dissertação (Mestrado em Geografia) - IGEO, Universidade Federal do Rio de Janeiro. Rio de Janeiro.

MAZURAS, M. (2013) BR-010 - Belém-Brasília, uma estrada brasileira. São Caetano do Sul: Editora Casa Maior.

NOGUEIRA, W. C. (1977) Pires do Rio: marco da história de Goiás. Goiânia: Roriz.

OLIVEIRA, J. K. (1975) Por que construí Brasília. Rio de Janeiro: Edições Bloch. SANTOS, M. (1997) A natureza do espaço. $2^{a}$ ed. São Paulo: Hucitec.

TEIXEIRA NETO, A. (2008) Os caminhos de ontem e de hoje em direção a GoiásTocantins. Boletim Goiano de Geografia, vol. 21, $\mathrm{n}^{\mathrm{o}}$ 1, jul. Goiânia. pp. 51-68. Disponível em: <http://www.revistas.ufg.br/index.php/bgg/article/view/4206>. Acessado em: 15 set. 2014.

VALVERDE, O.; DIAS, C. V.. (1967) A rodovia Belém-Brasília - estudo de geografia regional. Rio de Janeiro: IBGE. 